\title{
O ENSINO DE FILOSOFIA PARA CRIANÇAS
}

\section{Juliana Tibério ${ }^{1}$}

\begin{abstract}
RESUMO: O presente artigo tem como tema elucidar a importância do programa de filosofia nos anos iniciais para a formação da criança. A investigação deste tema é conduzida a partir do seguinte problema: por que é necessário o ensino de filosofia nas séries iniciais? O programa de filosofia para crianças é um método elaborado pelo filósofo americano Matthew Lipman, no final da década de 60. O objetivo geral desta pesquisa é mostrar como Lipman transformou a sala de aula tradicional em uma comunidade de investigação através do ensino de filosofia. Em seguida, apresentar sua chegada ao Brasil. A partir disso, buscou-se validar a hipótese de que o ensino de filosofia para crianças substitui o "aprender a filosofia" para o "aprender a filosofar", apostando no desenvolvimento da autonomia do sujeito. Desse modo, o processo de aprendizagem é uma descoberta coletiva através de discussões de conceitos e debates substituindo a memorização de conteúdo do ensino tradicional. A metodologia utilizada para produção desse estudo foi à pesquisa bibliográfica. $O$ artigo se justifica, prioritariamente, pela ausência do ensino de filosofia nos anos iniciais, principalmente, nas escolas públicas.
\end{abstract}

Palavras-Chave: Filosofia; Crianças; Pensar.

\section{TEACHING PHILOSOPHY TO CHILDREN}

ABSTRACT: This article has as its theme to elucidate the importance of the philosophy program in the early years for a child's education. The theme investigation is conducted from this following problem: why is it necessary to teach philosophy in the early grades? The philosophy program for children is a method devised by the American philosopher Matthew Lipman, not in the late 1960s. The general objective of this research is to show how Lipman transformed the traditional classroom into a research community through the teaching of philosophy. Then, present your arrival in Brazil. From this, we tried to validate the hypothesis that teaching philosophy to children substitutes "learning philosophy" to "learning to philosophize", betting on the development of the subject's autonomy. In this way, the learning process is a collective discovery through the concept of concepts and debates replacing the memorization of traditional teaching content. The methodology used to produce this study was bibliographic research. The article is justified, primarily, by the absence of teaching philosophy in the early years, mainly in public schools.

Keyords: Philosophy; Children; Think.

\section{INTRODUÇÃO}

\footnotetext{
${ }^{1}$ Graduada em Filosofia pela Universidade Estadual do Oeste do Paraná - UNIOESTE. Mestranda do Programa de Pós-Graduação em Filosofia pela Universidade Estadual do Oeste do Paraná - UNIOESTE. E-mail: juh_ana_gt@hotmail.com
} 
O presente artigo tem como tema a relevância do programa de filosofia para crianças nos anos iniciais. O objetivo é mostrar como o filósofo americano Matthew Lipman transformou a sala de aula tradicional em uma comunidade de investigação através do ensino de filosofia. Desse modo, o ensino da filosofia para crianças contribui para o "despertar" de uma consciência mais responsável pela educação.

Através de uma breve análise sobre como se concebe a infância é possível perceber que ela traz a criança como um ser ingênuo e totalmente dependente de um adulto. E foi pensando na criança e na sua formação que o filósofo americano Matthew Lipman (1923-2010) desenvolveu o programa de filosofia para crianças no final da década de 60 .

O presente artigo foi desenvolvido em três partes: a primeira parte mostra como Lipman percebeu a necessidade de se trabalhar filosofia na infância, e apresenta qual o é objetivo do programa ao estabelecer uma reconstrução da filosofia tradicional, que traz uma nova estratégia para a formação crítica dos jovens.

A segunda parte trata-se de como o filósofo americano desenvolveu o seu programa. Foi através de reflexões sobre como Sócrates trabalhava a filosofia que Lipman desenvolveu seu programa para solucionar certos problemas encontrados na educação tradicional. O filósofo mostra que a boas razões para pensar que o modelo de comunidade de investigação - aquele que é um espaço onde o educando aprende a investigar e a compartilhar e colaborar com os outros membros da comunidade (professor e alunos) - serve para qualquer sala de aula. Através desse modelo, os estudantes poderão pensar de forma independente. É por meio da filosofia da infância que Lipman destaca o direito que a criança tem ao raciocínio e aponta como o ensino da ética, da filosofia social e a relação com o outro através das expressões/personalidade é importante para o desenvolvimento da criança e a sua formação de comunidade.

A terceira parte mostra como foi à chegada do Programa de Filosofia para crianças ao Brasil. Em seguida, é exposto um projeto realizado com estudantes da $5^{\circ}$ série do Ensino Fundamental em uma escola pública da cidade de Cascavel, PR. O projeto realizado na escola demonstra a possibilidade do ensino de filosofia enquanto um espaço para que os educandos possam praticar o hábito de reflexão, investigação e 
argumentação, evidenciando que todos podem passar pela experiência filosófica e que ela gera bons frutos.

Com a renovação do ensino sugerido por Lipman, os professores poderão diminuir o transmitir de conhecimentos prontos e conseguirão orientar as crianças na busca de suas necessidades intelectuais. E os estudantes poderão desenvolver seu próprio pensar através de questionamentos e investigando as informações que lhe são oferecidas. Desse modo, o ensino de filosofia para crianças contribui para o "despertar" de uma consciência mais responsável pela educação.

\title{
O ENSINO DE FILOSOFIA PARA CRIANÇAS
}

O que é infância? Sabe-se que a infância é o início da vida humana, porém, associado a este conceito surgem certos pensamentos sobre a infância que o homem precisa se desprender. Tais pensamentos envolvem a criança como um sujeito totalmente dependente de um adulto e sem autonomia como afirma Bernardina Leal em seu texto "Leituras da infância na poesia de Manoel de Barros" (2004):

\begin{abstract}
Afirma-se que a crinaça carece de experiência, que necessita do auxilio adulto, que precisa ser protegida, que ainda não está preparada...Considera-se também a infância um periódo de ausência de responsabilidades, de falta de autonomia ou mesmo de não seriedade. Há ainda quem julgue a criança incapaz de compreender ou de fazer compreensível pela não-incorporação de um repertório linguistico "adulto" e "culto" e, em consequência, demoradamente construído (p. 20).
\end{abstract}

Dessa forma, leva-se a ideia de que o adulto pode preencher o que "falta" em uma criança.

Sabe-se que as crianças precisam de cuidados, uma vez que o cuidado é a fonte da amizade, do amor, do compromisso. No entanto, a concepção de que a criança precisa sempre de um adulto está as transformando em seres frágeis e incapazes que precisam sempre de um adulto para controlá-las. Desse modo, percebe-se que as crianças estão sendo educadas para submissão às regras do que para sua própria formação. 
E foi pensando nas instabilidades e na formação da criança que o americano Matthew Lipman desenvolveu o programa de Filosofia para Crianças, que surgiu no final da década de 60 e veio se espalhando pelo mundo. O programa de Filosofia para Crianças é uma reconstrução da filosofia tradicional que traz uma nova estratégia para a formação crítica dos jovens. Seu objetivo é desenvolver as habilidades cognitivas incentivando a reflexão e sempre valorizando as experiências da criança e o cuidado, pois, segundo Lipman, o cuidado é um pensamento afetivo que valoriza a capacidade da criança, não a trata como um ser totalmente dependente. Para Marie-France Daniel (2000) "[...] o objetivo do currículo de Filosofia para crianças [...]" na visão Lipamn é "[...] de propiciar uma formação fundamental à criança, valorizando ao mesmo tempo sua experiência cotidiana, estimulando-a, assim, a praticar a investigação do significado" (p.18).

A longa experiência de Lipman no ensino universitário fez com que ele percebesse que quando um adulto chega ao ensino superior seu pensamento já está formando. Dessa forma, Lipman chega à conclusão de que a aprendizagem dos pensamentos autônomos e críticos devem ser realizados nas escolas primárias, através do ensino da filosofia para as crianças.

Os termos "filosofia" e "crianças" trouxe uma série de contradições, uma delas era que as pessoas acreditavam que seu objetivo era memorização de sistemas filosóficos de Platão e Aristóteles. No entanto, Matthew Lipman explica que o objetivo não é criar pequenos sábios, mas sim, ensinar o exercício e incentivar o habito de refletir. Diz Lipman (2000):

[...]objetivo ao associar as crianças ao processo filosófico não é produzir pequenos sábios, mas fazer que aprendam, orientados pelos valores e pelos ideais humanas, a pensar de forma mais prática. A filosofia para crianças visa levar os jovens a pensar de forma mais ponderada e justa e a inculcar-lhes o hábito de refletir quando se encontrem numa situação problemática ou conflituosa (p.10).

O Programa de Filosofia para Crianças de Lipman busca um espaço investigativo-dialógico, na qual, orientados por educadores, tem como objetivo melhor compreensão de temáticas filosóficas. Tais temáticas são aquelas questões que todos os seres humanos fazem, questões sobre liberdade, verdade, justiça entre outras. As 
respostas dessas questões é o que molda a forma de ser gente, a forma de agir, a de pensar e a forma de se organizar socialmente. Através dessa prática, os educandos desenvolvem a sua capacidade cognitiva, isto é, um "pensar melhor".

Mas, o que é um espaço investigativo-dialógico? É um espaço para que as crianças e os jovens aprendam a investigar através do diálogo. Ou seja, é um espaço onde o educando aprende a investigar e a compartilhar e colaborar com os outros membros da comunidade (professor e alunos).

Segundo Lipman, fazer filosofia exige dialogo e comunidade, algo que para ele não se encontra em uma sala de aula tradicional. O filósofo americano nomeia o ensino tradicional de Paradigma padrão da prática. Isto é, a transmissão que o professor faz de conhecimentos prontos para os educandos. De acordo com Lipman:

\footnotetext{
O fazer filosofia exige conversação, diálogo e comunidade que não são compatíveis com o que se requer na sala de aula tradicional. A filosofia impõe que a classe se converta numa comunidade de investigação, onde estudantes e professores possam conversar como pessoas e como membros da mesma comunidade; onde possam ler juntos, apossar-se das ideias conjuntamente, construir sobre as ideias dos outros; onde possam pensar independentemente, procurar razões para seus pontos de vista, explorar suas pressuposições; e possam trazer para sua vida uma nova percepção de que é descobrir, inventar, interpretar e criticar (LIPMAN,1990, p.61. apud LORIERI, 2004, p. 157).
}

Até os dias de hoje, os programas escolares não dão muita importância à compreensão de conceitos de forma geral. Sempre é passado para os professores que os alunos devem seguir determinadas normas. No entanto, não basta que os alunos conheçam as normas, é necessário que eles tenham conhecimento sobre os critérios dessas normas, para que possam "[...] distinguir os processos corretos de pensamento dos processos incorretos, porque enquanto eles ignorem, não poderão se tornar responsáveis por suas próprias atividades mentais" (LIPMAN, 2000, p. 10). Portanto, nada mais adequado que a filosofia para preencher esta deficiência nos programas escolares.

Adiante, segue-se com a exposição do Programa Filosofia para Crianças de Matthew Lipman.

\section{A CONCEPÇÃO DE MATTHEW LIPMAN}


O programa de Lipman estabelece dois objetivos fundamentais: a iniciação filosófica; e o cultivo das habilidades de pensamentos das crianças. Para se compreender os dois objetivos é necessário à compreensão do ensino da filosofia como parte fundamental do currículo.

O filósofo Americano recorre aos ensinamentos de Sócrates (Maiêutica), mostrando que a filosofia possui um gigantesco tesouro pedagógico capaz de fundamentar a educação nos princípios da reflexão. Sócrates nunca estabeleceu qual era a idade para se "fazer" filosofia, pois, segundo filósofo ateniense, fazer filosofia não tem haver com idade, tem haver com a habilidade em refletir sobre aquilo que se considera importante. E se a educação é algo importante que se ocupa com o destino do pensamento humano, então é necessário que ela deva "[...] ensinar às crianças "como" pensar, e não em "que” pensar" (DANIEL, 2000, p.20).

Observando o sistema educacional atual, podemos perceber que ele é imperfeito, e que suas imperfeições são responsáveis por grandes consequências. Podemos observar os reflexos dessas imperfeições nas graves circunstâncias em que o mundo se encontra atualmente. Diz Lipman:

Se lamentamos nossos líderes e nossos eleitores por serem egoístas e não esclarecidos, devemos lembrar que eles são produtos de nosso sistema educacional. Se protestamos, como um fator atenuante, que eles são também produtos de lares e famílias, devemos lembrar que os pais e avós dessas famílias são igualmente produtos do mesmíssimo processo de educação (LIPMAN, 1990, p. 33).

Se o sistema educacional atual é imperfeito, então qual é o ideal que a prática pedagógica busca aproximar-se? Provavelmente, essa é a principal questão que a educação tem de enfrentar. No entanto, talvez seja necessário fazer uma questão diferente: em qual aspecto a educação mais deixa a desejar? Isto é, qual aspecto ela mais nos desaponta? Ao responder essa questão automaticamente respondemos à primeira: "[...] o maior desapontamento da educação tradicional é o seu fracasso em produzir pessoas que se aproximem do ideal de racionalidade" (LIPMAN, 1990, p. 34). Portanto, para se aproximar do "ideal de racionalidade" é que Lipman aposta na filosofia. Pois, é na filosofia que o raciocínio é efetivamente cultivado. Melhor dizendo, a filosofia é a 
disciplina que melhor "[...] nos prepara para pensar nos termos das outras disciplinas [...]” (LIPMAN, 1990, p. 35), por isso ela tem um papel central - tanto nas séries iniciais como nas posteriores - do processo educacional.

Lipman afirma que os componentes da educação possui um tipo de inter-relação "bizarra". Em outras palavras, se objetivo principal da educação é o aprender, por que a avaliação é a força que dirige o sistema educacional se ela não valoriza o aprendizado do educado? O efeito desse modelo é mais memorização do que o incentivo ao pensar. Isso não quer dizer que os educandos precisam de avaliações melhores, mas o que se precisa perguntar é: em que mundo se pretende viver? Pois, a educação é um reflexo das características desse mundo. Diz Lipman:

[...] o modelo de aquisição de informação que domina a educação, em vez de estimular as crianças a pensarem por si mesmas, seja um fracasso até em seus próprios termos, pois ficamos constantemente assustados com o pouco que nossas crianças parecem saber sobre a história do mundo ou sobre a sua organização política e econômica (LIPMAN, 1990, p. 36).

Lipman declara que há boas razões para pensar que o modelo de comunidade de investigação serve para qualquer sala de aula. Esse modelo traz a "[...] prática reflexiva que pensa nas disciplinas relativas ao mundo e sobre os seus pensamentos sobre o mundo" (LIPMAN, 1990, p. 37). E através desse modelo percebe-se que a prática pode ser incluída dentro de outras comunidades maiores e essas dentro de outras ainda maiores, claro que todas precisam seguir o mesmo procedimento investigativo.

Com o ensino da filosofia, Lipman propõe aos educandos um encorajamento para que eles possam pregar métodos e ferramentas de investigação, para:

[...] que possam, competentemente, avaliar evidências, detectar incoerências e incompatibilidades, tirar conclusões válidas, construir hipóteses e empregar critérios até que percebam as possibilidades de objetividade com relação a valores e fatos (LIPMAN, 1990, p. 22).

O filósofo americano compõe um recurso didático que ele chama de novelas filosóficas que consistem em obras com personagens fictícios, a escrita de forma simples e discussões em vários temas filosóficos que são abordados. Lipman afirma que as novelas filosóficas chamam muito a atenção das crianças, assim, o educador 
consegue provoca-las a debater os temas filosóficos. Essa metodologia visa estimular a formação da comunidade investigativa na sala de aula e a capacidade de "[...] discussão autocorretiva de questões consideradas importantes e problemáticas" (LIPMAN, 1990, p. 37).

Nestas novelas, a textualidade dominante é o diálogo. Lipman traz às reflexões filosóficas em textos levados a sala de aula. Seu objetivo é garantir que as crianças não tenham nenhuma vantagem e nem desvantagem. Isto é, todos têm suas bagagens culturais, mas na hora da reflexão filosófica todos terão disponíveis as mesmas informações.

Em relação ao espaço o professor deve aproveitá-lo tanto dentro da sala como fora dela. É importante que todos os educandos estejam acomodados e todos tenham o mesmo direito, isto é, nenhum estudante pode estar em algum assento privilegiado. $\mathrm{O}$ ideal para ensinar o filosofar é o circulo e que o professor também faça parte dele. Afirma Walter Kohan:

Um círculo é uma figura na qual todos os seus pontos são equidistantes do centro e na qual nenhum ponto tem posição vantajosa. Por isso, num círculo todos podemos nos ver e nenhum de seus integrantes está em vantagem ou desvantagem em ralação ao resto (KOHAN, 1997, p. 90).

Nos dias atuais a palavra "pensar" está na boca de todos, e existem alternativas para que o pensar faça a diferença. Deve-se esperar de uma comunidade educacional que seu objetivo seja produzir estudantes reflexivos e isso pode acontecer se a comunidade educacional apostar no ensino das habilidades de pensamento.

Vista que as habilidades do pensamento é o que falta na educação, muitos coordenadores estão cobrando de seus professores que além de ensinar suas matérias ensine também está modalidade. No entanto, como afirma Lipman:

Os professores, por seu lado, sentem-se cada vez mais pressionados: as escolas de educação que frequentaram não os prepararam para ensinar habilidades de pensamento, e a maioria deles sente que embora competente, só pode ensinar o que aprendeu a ensinar (LIPMAN, 1990, p. 47).

Os professores se sentem culpados por tal deficiência ao lecionar. E o que mais preocupa toda a comunidade escolar é como vão treinar os professores para ensinar tais 
habilidades. Vista que, não se sabe o que fariam com esse treinamento se recebessem e nem se faria muita diferença, pois, como diz Lipman, toda essa conversa sobre habilidades do pensamento não mostra o problema em si, apenas aponta os sintomas do problema.

O que chama bastante atenção no sistema educacional é o fato de que para iniciar uma disciplina nova devem ser fornecidas anteriormente habilidades necessárias para que o estudante possa ter domínio da disciplina atual. No entanto, Lipman alerta para o fato de que "[...] os professores de qualquer série escolar ensinam aos seus estudantes as habilidades necessárias às séries subsequentes e não as habilidades necessárias à sua própria disciplina, pois estas foram trabalhadas anteriormente" (LIPMAN, 1990, p. 50). Um exemplo seria o professor da quarta série que prepara seus estudantes para enfrentar o currículo da quinta série. Com tudo, os professores não estão preparados para ensinar habilidades cognitivas de conteúdos mais avançados e se sentem, na visão do filósofo americano, desesperados. Em vista disso, como resolver este problema? Será que a filosofia é a disciplina que realmente prepara o "pensar" nas outras Disciplinas?

Não precisa ser muito perspicaz para perceber que a filosofia é a disciplina que ensina a "pensar outras disciplinas". Todavia, existem aqueles que afirmam que a filosofia não tem o papel de "fazer pensar", mas, apenas de nos fazer "pensar melhor". Como fiz Lipman (1990): "Presumivelmente, ele quer dizer que a filosofia não nos motiva a pensar, mas nos faz pensar melhor porque fortalecem as habilidades de raciocínio, de investigação e de formação de conceitos, habilidades que já temos" (p. 51). Contrariando este pensamento, não é atoa que a filosofia é atraída a responder questões problemáticas, é a procura pelo problemático que gera o pensamento, a reflexão. Desse modo, “[...] quando encontramos aqueles prefixos "filosofia da ciência", "filosofia da história" e assim por diante, estamos lutando com os aspectos problemáticos daquelas disciplinas" (LIPMAN, 1990 p. 52).

O que Lipman quer mostrar é que o pensar é o verdadeiro fundamento do processo educacional. E que, as habilidades para pensar as outras disciplinas têm que ser desenvolvidas antecipadamente, e com isso, a filosofia precisa deixar de ser algo trabalhado apenas no ensino médio e nas universidades. Ela precisa se tornar uma 
matéria do ensino fundamental, uma matéria trabalhada desde os anos iniciais. Uma disciplina que prepara os estudantes para pensar outras disciplinas.

Mas como funciona a filosofia na infância? A filosofia é divida entre refletir e responder questões que envolvem habilidades específicas e experiências humanas. As habilidades específicas são relacionadas às variedades do raciocínio. Já as experiências humanas envolvem a estética, a moral, o social e o religioso. A infância é uma dimensão legítima do comportamento humano e da experiência humana, e que, "[...] não é menos habilitada ao tratamento filosófico que as outras dimensões para as quais já existem filosofias" (LIPMAN, 1990, p. 215, grifo nosso).

Sabemos que nem toda criança é um filósofo, porém, todo filósofo já foi criança. Já que a criança preenche os requisitos acima (habilidades específicas e experiências humanas), então, o ensino da filosofia para crianças assegura implicações positivas para "[...] a filosofia social, metafísica, filosofia do direito, ética, filosofia da educação e outras áreas filosóficas" (LIPMAN, 1990, p. 216). O objetivo aqui é mostrar como o trabalho nessas áreas é importante para o desenvolvimento da criança.

A criança tem direito a raciocinar, vista que ela é um ser curioso por natureza. Sabe-se que as crianças fazem perguntas frequentemente aos adultos, no entanto, entende-se também que nem todas as perguntas feitas recebem respostas, pois, muitas vezes os adultos estão ocupados de mais e não se interessam em discutir com as crianças, ou querem protegê-las de tal conhecimento como "[...] a si próprios do uso irresponsável de tal conhecimento" (LIPMAN, 1990, p. 217). Assim, nesse sentido, o direito da criança de perguntar envolve o direito do adulto se quer responder ou não.

Embora a criança esteja no direito de perguntar, o adulto pode, sem nenhuma injustiça, não querer responder ou apenas dar uma resposta sem muito fundamento. Apesar da escolha do adulto, o direito de perguntar da criança não deveria ser negligenciado, pois, a negação de resposta implica no direito que a criança possui de aprender com aquilo que o adulto poderia ter expressado. Por isso, a questão aqui levantada é o direito da criança de engajar em uma investigação cooperativa.

Visto que as crianças podem fazer filosofia, mostra a necessidade de desenvolver filosofias da infância. Pois: 
[...] se as crianças podem raciocinar quando começam a falar, e se podem fazer filosofia quando começam a raciocinar, a aliança atual entre a ética filosófica e a psicologia do desenvolvimento começará a mostrar sinais bemvindos de força. Seria o caso de que cada estágio do seu crescimento as crianças pudessem engajar-se na investigação e a ética não precisasse mais ser corrompida, como é agora, com aquela manipulação doutrinável dos pontos de vista marais e atitudes das crianças, que se denomina "educação moral" (LIPMAN, 1990, p. 218).

Visto isso, vemos que a filosofia da infância seria mais produtiva por novos trabalhos na teoria da ética. Desse modo, deve-se levar mais em consideração a capacidade da criança de se engajar em diálogo racional.

Além da ética, a filosofia social também deve ser mais bem trabalhada. Pois, o incentivo a formação de comunidades na infância, onde "[...] franqueza e confiança misturam-se livremente com admiração, procura e raciocínio” (LIPMAN, 1990, p. 222) proporciona um apoio necessário e social na fase crítica onde às crianças começam o distanciamento das suas famílias para se estabelecer como indivíduos maduros e responsáveis.

Segundo Lipman, geralmente pensamos na personalidade do educando não como algo que nasce com ele, mas como algo que ele conquista gradativamente. Hoje em dia, a "iniciação" da personalidade é colocada em uma idade mais precoce e o começo da maturidade mais adiante. Apesar de existir vários estudos relacionados sobre a personalidade e a racionalidade da criança, que aqui não entraremos, este tema permanecerá perseguindo a filosofia. Pois:

[...] se recusamos reconhecer a racionalidade da criança, não podemos nos engajar satisfatoriamente no dialogo filosófico com elas, porque não podemos aceitar suas expressões [personalidade] como razões. Se não podemos fazer filosofia com as crianças, privamos sua educação mais significativa (LIPMAN, 1990, p. 223).

E se negamos uma educação mais significativa, "[...] asseguramos que a ignorância, irresponsabilidade e mediocridade que prevalecem atualmente entre os adultos continuarão a acontecer” (LIPMAN, 1990, p. 223). Isto é, não haverá quase nenhum avanço.

\section{O PROGRAMA DE FILOSOFIA PARA CRIANÇAS NO BRASIL}


Pensar o exercício da filosofia nos anos iniciais aqui no Brasil parece algo complexo, mas não existe melhor momento visto nossa situação atual, onde pessoas acreditam em tudo que é repassado pela internet, sem fazer uma investigação para saber se aquilo é verdadeiro ou uma fake News.

O Programa de Filosofia para Crianças chegou ao Brasil através da professora Catherine Young Silvia que criou o Centro Brasileiro de Filosofia para Crianças (CBFC). O programa foi fundado em janeiro de 1985 sem fins lucrativos, sua primeira sede foi em São Paulo. Para trabalhar o ensino da filosofia de Lipman, tanto as escolas públicas quanto as particulares contam com algumas novelas traduzidas e adaptadas para a cultura brasileira. São elas: Rebeca, ideal para a Pré-escola (5/6 anos); Issao e Guga, destinado para $1^{\circ}$ e $2^{\circ}$ ano; Pimpa, para crianças de $3^{\circ}, 4^{\circ}$ e $5^{\circ}$ ano; A descoberta de Ari dos Telles, para $5^{\circ}$ até $7^{\circ}$ ano; e Luísa, indicado para o $8^{\circ}$ ano. Além desses materiais didáticos, também é possível encontrar materiais complementares como textos e livros curtos que foram desenvolvidos pelos currículos do Programa.

O programa de filosofia para crianças ganhou força nacional através dos meios de comunicação, assim, aumentou o número de pessoas envolvidas como o programa.

Em 1993 a professora Catherine Young Silvia veio a falecer e quem assumiu seu lugar foi à professora Melaine Clarie Young Silva. Atualmente Ricardo Young está à frente do programa com a colaboração de vários professores. Por volta da metade dos anos 80 até dos dias atuais foram fundados novas filiais e centros regionais para representar o programa. Visto o progresso do ensino de filosofia para crianças e tantos profissionais a disposição, ainda é lamentável que o programa não fosse acrescentado em todas as escolas do Brasil.

No entanto, o artigo "Filosofia para crianças: uma experiência no Ensino Fundamental Público" traz a experiência realizada com estudantes da $5^{\circ}$ Série do Ensino Fundamental, que foi desenvolvida e implantada como projeto em uma escola pública de Cascavel, PR. O objetivo do projeto foi elaborar espaços para discussões coletivas entre a comunidade escolar, onde pudessem refletir sobre as inquietações educacionais, pessoais e sociais.

Para que o projeto pudesse ser implantado, foi necessário que os professores idealizadores conhecessem a fundo a proposta "Filosofia para Crianças" e 
diagnosticassem a comunidade escolar na qual iria trabalhar o projeto. A partir daí, os educadores desenvolveram hábitos filosóficos, como a formulação de questões, diálogos investigativos, entre outros.

Os professores responsáveis pelo projeto fizeram uma pesquisa com professores da rede estadual. O objetivo dessa pesquisa foi investigar como os educadores viam a disciplina de filosofia no contexto em que se encontra o país atualmente, focaram especialmente na importância do ensino de filosofia no ensino fundamental e constataram que:

\begin{abstract}
A Filosofia é considerada importante no espaço escolar, inclusive no ensino fundamental, uma vez que pode oportunizar o resgate das relações humanas, pois é no diálogo, na reflexão, na observação e no questionamento da realidade que o aluno poderá desenvolver a elaboração de conceitos e o pensamento crítico reflexivo, de forma que tais posicionamentos corroborem com o que os autores trabalhados ao longo deste trabalho já afirmaram ( PEDROSO E MALACARNE, 2008, p. 9).
\end{abstract}

Segundo Lipman, se a criança não tiver uma educação de qualidade ela cairá na ignorância que prevalece em muitos adultos atualmente. Portanto, a “[...] educação significativa abre possibilidade para novas relações sociais na estruturação da personalidade e da construção de identidade do aluno" (PEDROSO E MALACARNE, 2008, p. 9-10). Desse modo, o ato de aprender é significativo quando está relacionado com a vida cotidiana do educando e com o hábito de reflexão.

Ao realizar a pesquisa de campo com a comunidade escolar, os idealizadores do projeto constataram que os educandos não tinham o hábito de perguntar aos professores os conteúdos para sanar suas dúvidas. Muitos alegavam ter vergonha e outros afirmavam que não gostavam de perguntar. Segundo o artigo:

\begin{abstract}
Nessa questão, se evidência a pouca interação entre professor e aluno, bem como a falta da oportunidade ao diálogo. A vergonha, no contexto, é sinônima de medo de ser ridicularizado pelos colegas e por que não fizer pelos professores, o qual, em muitos casos não oportunizou de dialogar com seus alunos (PEDROSO e MALACARNE, 2008, p. 10).
\end{abstract}

No entanto, quando as perguntas se tratavam sobre suas diferenças e relacionamentos sociais e familiares, os educandos expressavam bem suas opiniões. Desse modo, pode-se constatar a importância das reflexões filosóficas, pois, quando 
questionados os estudantes sentiram que suas ideias foram valorizadas. Por isso, praticar a reflexão traz uma educação significativa e de qualidade.

O projeto também foca na família dos educandos. Segundo seus idealizadores, uma das questões levantadas é se os pais ou responsáveis pelos estudantes realizavam discussões que envolvem os seguintes temas: justiça, certo e errado, bem e mal, felicidade, liberdade, entre outro. Os responsáveis afirmaram que desde cedo é importante ensinar o que é certo e errado, por isso, eles contam com o apoio da escola. Desse modo, observa-se mais uma vez como o ensino de filosofia pode fazer a diferença, pois, ela ensina o educando a refletir sobre o que é considerado certo e errado, o que é a liberdade, como a justiça e outras coisas funcionam.

Quando questionados sobre a importância da filosofia na escola, os pais consideraram essencial, pois, ela abre para o diálogo no dia a dia e abre possibilidade para a compreensão do respeito com a família e sociedade. Em outras palavras:

\footnotetext{
Na escola, a filosofia contribui na construção de um pensamento crítico e reflexivo para aquisição dos conteúdos apresentados em sala de aula. A escola como espaço social na qual a educação formal ocorre num contexto específico com a intencionalidade de instrumentalizar os indivíduos para que alcancem a autonomia e respondam aos desafios do ambiente assim como busquem melhorar este mesmo cotidiano PEDROSO e MALACARNE, 2008, p. 11).
}

Apesar do programa de filosofia para crianças ser pouco conhecido no Brasil, Lipman criou um ótimo programa que, para os professores idealizadores do projeto, teve grande significado na rotina escolar, evidenciando um processo educativo que valoriza o educando e a construção da sua identidade. Portanto, pode-se observar que os temas levados para a sala de aula não foram apenas questões sobre o mito da caverna de Platão, ou temas centrais de outros filósofos. Mas, vivências do dia a dia dos educandos que permitiu que cada um ali formasse sua própria consideração, expressão e ideias, sem serem refutadas por algum adulto.

\section{CONCLUSÃO}

Portanto, percebe-se que filósofos como Sócrates nunca estabeleceram uma idade para se "fazer" filosofia. Porém, ao decorrer do tempo, a filosofia se destinou 
apenas para os adultos. E foi através do seu trabalho no meio universitário que o filósofo americano Matthew Lipman percebeu que os adultos chegam ao ensino superior com seu pensamento já formando. Então, Lipman ressalta a importância da filosofia nas séries iniciais para a formação da criança.

Lipman encontra várias falhas no sistema educacional atual, mostrando que enquanto trabalha-se a memorização dos conteúdos e consideram as crianças como seres que são totalmente dependentes, consequentemente os futuros adultos terão muitas dificuldades na hora de elaborar um raciocínio crítico.

Com a renovação do ensino criado pelo filósofo americano, os professores diminuíram o transmitir de conhecimentos prontos e poderão orientar as crianças na busca de suas necessidades intelectuais e os estudantes poderão desenvolver seu próprio pensar através de questionamentos e investigando as informações que lhe são oferecidas.

É fato que inserir o ensino de filosofia nos anos iniciais não é um trabalho fácil. São necessárias políticas públicas que envolvam seu ensino, é necessário capacitar nossos profissionais e mostrar para o país (Brasil) que o ensino da filosofia é importante desde a infância. É importante porque seu ensino traz para a criança a capacidade de se maravilhar com o mundo, e través deste artigo fica claro que estimular o pensamento filosófico da criança ajuda na construção da sua identidade.

É importante destacar mais uma vez que o objetivo do programa não tem relação somente em refletir textos clássicos de Platão, Aristóteles, e outros filósofos. Seu benefício traz ao desenvolvimento cognitivo da criança o pensamento crítico, melhor vivência em sociedade e também influência no desenvolvimento emocional infantil, já que a criança adquire confiança para se relacionar e conhecer o que está em sua volta.

Esta breve análise da concepção de Lipman evidência como o ensino da filosofia para crianças contribui para o "despertar" de uma consciência mais responsável pela educação do país, no sentido de formar cidadãos mais atentos e aptos a discutir e a decidir por si mesmo.

Lipman deixa um legado bastante diversificado. Isto é, o filósofo americano plantou a semente de um grandioso projeto educacional que permite libertar a filosofia para todas as idades. Mas infelizmente, seu ensino ainda é pouco valorizado e á uma batalha muito grande pela frente até a filosofia ser realmente para todos. 


\section{REFERÊNCIAS BIBLIOGRÁFICAS}

LEAL, Bernadina. A infância na poesia de Manoel de Barros. In: LUGARES DA INFÂNCIA: FILOSOFIA. ed DP\&A, coleção Sócrates. p 19-30, 2004.

DANIEL, Marie-France. A filosofia e as crianças; prefácio de Matthew Lipman. Tradução de Luciano Vieira Machado. Nova Alexrandia, 2000.

LORIEN, Marcos Antônio. O trabalho de filosofia com crianças e jovens nos últimos vinte anos. In: LUGARES DA INFÂNCIA: FILOSOFIA. ed DP\&A, coleção Sócrates. p 155-175, 2004.

LIPMAN, Matthew. A Filosofia vai à escola. Tradução de Maria Elice de Brzezinski Prestes de Lucia Maria Silva Kremer. São Paulo: Smumus, 1990. - (Novas buscas em educação; v. 39).

KOHAN, Walter. Sugestões para implementar a filosofia com crianças em escolas. 1997.

SARDI, Ségio. Ula brincando de pensar. Ed Vozes.

PEDROSO, Maria Miranda. MALACARNE, Vilmar. Filosofia para crianças: uma experiência no ensino fundamental público. Dia dia educação. 2009. Disponível em: http://www.diaadiaeducacao.pr.gov.br/portals/pde/arquivos/2418-8.pdf. Acessado em: 28 de dez. de 2019.

PEDROSO, Maria Miranda. MALACARNE, Vilmar. "Filosofia para crianças" Educação para o "Pensar": Um olhar Pedagógico. Docplayer. 2008. Disponível em: https://docplayer.com.br/17928243-Filosofia-para-criancas-educacao-para-o-pensar-umolhar-pedagogico.html. Acessado em: 28 de dez. de 2019. 